solution in the juice of tinned fruits; (4) the action of poisonous gases; (5) that it is due to an infection.

In regard to suggestions 1 and 4 it is sufficient to point out that this condition was common in the Federal Army during the American Civil War, when in the Wilderness that Army was fighting under conditions of exposure and hardship similar to those now imposed upon the men on the Western front. But the Federal troops were strangers to both chloride of lime in their drinking water and poisonous gases in their trenches. Moreover, if poisoning by gas plays any part in this condition, the great increase in the use of gas shells, dating from the end of 1916, should have been followed by a corresponding rise in incidence, and this has not been the case.

As to the absence of vitamines, it is sufficient to point out that at the period under consideration preserved food formed only a small part of the rations, and there was no reason to suspect any shortage of these bodies.

If the consumption of tinned fruit has anything to do with causing the condition it ought to be proportionately more common among the officers than among the men, for much more tinned fruit is eaten in officers' messes than among the men. The fact is that the reverse is the case.

In pursuance of the view that the condition is of infective origin, various organisms have been isolated from the urines or nephritic cases, and in some instances vaccines prepared from them have been used in treatment. Recovery followed, but this is only surprising to those who disbelieve in vaccine therapy. Tytler and Ryle ${ }^{2}$ recovered a streptococcus forming greenish colonies on blood agar from nephritic urine; they recovered similar organisms from controls, but in a smaller proportion of cases. They do not appear to attach much importance to this organism as an etiological possibility. Davies and Weldon $^{3}$ state that they have known instances of transmission of the disease to attendants, but the details given are so scanty that they can hardly be intended to serve as evidence.

There is one factor or group of factors common to all cases occurring in the B.E.F. in France and to the outbreak during the American Civil War, and that common factor is excessive and prolonged fatigue in combination with exposure.

It has long been recognised that albumin, often in large amounts, and casts are almost constantly present in the urine of healthy adults after such exertion as is entailed by ordinary athletics. This albuminuria is stated always to clear up and to leave no ill-results or predisposition to renal trouble. Such is undoubtedly the case in athletes, who after the game is over can take as much rest as they please. Among soldiers under modern war conditions, however, the case is very different. The battle does not stop like a game; it continues for days, weeks, or months, and the soldier must participate until his unit is relieved. When not actually attacking or repulsing attacks, the soldier is engaged in digging, ration-carrying, wiring, or some other arduous work. His intervals for sleep are inadequate and short, and his rest is uncomfortable and broken. Unäer such circumstances it is conceivable that what in the athlete may be a passing symptom, may in the soldier become a morbid process.

Martin Fischer maintains that acute nephritis is due to a toxic acidosis. He regards the albuminuria of athletes as due to a physiological acidosis. The difference he looks upon as one of degree, not of kind. Osler remarks that "common febrile albuminuria ...... represents the first link in the chain leading to acute Bright's disease." May not the same remark apply to the albuminuria of exertion?

All things considered, it seems possible that the most fruitful line of research as to the causation of this condition would be on the alterations of metabolism produced by fatigue, meaning by fatigue the bodily state produced by exertion, lack of sleep, and exposure.

Such an investigation might well also throw light on the etiology of that large class of cases occurring in civilian life and usually described as nephritis a frugore, for clinically the difference between these and the "trench "nephritis cases does not seem to be great. The prognosis in "trench" nephritis seems to be slightly better than in the civilian disease, but this may be accounted for by the fact that the

2 Clinical and Pathological Notes on Trench Nephritis, W. H. Tytler and J. A. Ryle, Quarterly Journal of Medicine, Jannary, 1918. ${ }^{3}$ A Contribution to the Stuây of War Nephritis, F. C. Davies and R. P. Weldon, THE LANCET, July 28th, 1917. former condition occurs among more or less picked men. Various writers have called attention to the great frequency of pulmonary complications, particularly bronchitis, in the military cases. The obvious explanation of this would be the infection of an cedematous lung from a pre-existing mild bronchitis, such as is common enough among the men in the colder months. Tytler and Ryle, in the article above quoted, draw attention to a deposition of fibrin in the walls of the lung alveoli of some of their cases which came to post-mortem. This condition, they state, is not found in ordinary nephritis, and they regard it as pointing to the action of a local irritant. They also call attention to hæmorrhages into the spleen. It will be interesting to learn whether these changes can really be regarded as differentiating "trench" from civilian nephritis. The changes found by these investigators in the kidneys were apparently such as might well occur in a case of nephritis a frigore.

It would appear that the principal, if not the only, way in which " trench" nephritis differs from nephritis as seen in civil practice is in the greater frequency of its incidence. Acute nephritis is not a very common disease among civilians; the condition described above is decidedly common in the B.E.F., though exact figures as to its incidence per 1000 are not now obtainable. What is the factor common to both soldiers and civilians, but more potently effective among the former than the latter? Such a common factor is excessive and prolonged fatigue, combined with exposure to cold and wet.

In conclusion it may be stated that such evidence as is provided by the consideration of the above series seems to indicate that the condition known as "trench" nephritis differs little from nephritis as met with in civilian practice except in the greater frequency of its occurrence, and that it is either a primary acute nephritis or an exacerbation of pre-existing disease, induced by fatigue and exposure.

My thanks are due to Colonel T. R. Elliott, A.M.S., consultant physician to the Boulogne Base, through whose courtesy the organisation of the National Research Committee for following the after-histories of patients was placed at my disposal; to the medical officers of the home hospitals who filled in and returned the schedules, thus making possible the section on prognosis; and to the nursing staff of the wards at the base hospital in France, whose unflagging zeal made possible the collection of the clinical material.

\section{"OBSCURE EPIDEMIC ENCEPHALITIS."}

\section{SOME OBSERVATIONS ON BLOOD COUNTS AND} CEREBRO-SPINAL FLUID.

BY S. K. VAIDYA, M.R.C.S. ENG., D.T.M. \& H. CANTAB., L.M. \& S. ВомваY, \&O.,

ASSISTANT CLINICAL, PATHOLOGIST, LONDON HOSPITAL.

(From the Hale Clinioal Laboratory, London Hospital.)

WITH the object of ascertaining the condition of spinal fluid and blood in this disease I have examined a number of cases of "obscure encephalitis" under observation at the London Hospital.

\section{Findings in Epidemic Polionyelitis.}

I consider it material to refer briefly to the findings summarised in the Rockefeller Institute Monograph No. 4 (1912) and Dr. G. Draper's book on acute poliomyelitis (1917).

In the literature on poliomyelitis there are conflicting atatements about leucocyte counts. L. E. La Fetra, in New York, reported six cases with a leucocytosis running from 13,000 to 20,000 , while $\mathbf{E}$. Müller, in Germany, reported 15 cases with a leukopenia of from 3000 to 5000 . Though Gay and Lucas found leukopenia with lymphocytosis in monkeys, their leucocyte counts in human cases were $7800,12,200,11,600$ $17,400,12,000$, and 13,400. Dr. F. W. Peabody and his co-workers' results can be summed up as under.

"We have found in the blood of patients with poliomyelitis a constant and marked leucocytosis. If taken in connexion with other avallable evidence a leucocytosis of from 15,000 to 30,060 is distinetly suggestive of the disease in question, especially if the polymorphomolear cells are increased at the expense of the lymphocytes.

They find that this lencocytosis lasts for as many as seven reeks and is highest in the youngest children.

With regard to the spinal fluid " previous investigations have not been extensive nor have the examinations been careful." Gay and Lucas have recorded 75 to 100 per cent. 
of mononuclear cells. Dr. Peabody and his colleagues examined 233 fluids from 69 cases, and they found that almost all were clear, colourless, and watery. Only a few showed the slightest opalescence. The type of cell present in the fluid was almost always the mononuclear. Though Flexner and Lewis and Lucas all record polymorphonuclear cells in the spinal fluid of their experimental monkeys up to 72 hours from the time of inoculations, Lucas in his 11 preparalytic human cases found only mononuclear cells. It must be stated that 2 out of 6 prodromal stage cases of the Rockefeller Institute showed polymorphonuclear cells. However, Dr. Draper describes many abortive and preparaly tic cases in his book on acute poliomyelitis (1917), and he describes a "fluid whose clearness may or may not be impaired. It is rarely opalescent or turbid. Here at once is a groes point of difference from the fluid of cerebro-spinal meningitis." He also describes polynuclear cells which ar not polymorphonuclear cells in the very early stages, but which are replaced by the end of 24 to 36 hours by small lymphocytes which represent 90 per cent. of the total number.

As regards protein, all the investigators have recorded a more or less definite excess.

In effect, according to the American investigators, a leucosytosis of from 15,000 to 30,000 , combined with an excess of protein and a well-marked excess of mononuclear cells (small lymphocytes) in the spinal fluid is always present in cases of poliomyelitis. In a small percentage of cases polynuclear cells are said to occur in the spinal fluid in the prodromal stage.

Investigation of Cases of Epidemio Encephalitis.

My own results are as follows :-

Results of Examination of Blood and Cerebro-spinal Fluid.

\begin{tabular}{|c|c|c|c|c|c|c|c|c|c|c|c|}
\hline \multirow{3}{*}{ No } & \multirow{3}{*}{ Sex } & \multirow{3}{*}{ Age. } & \multirow{2}{*}{\multicolumn{2}{|c|}{$\begin{array}{c}\text { Cerebro-spinal } \\
\text { fluid. }\end{array}$}} & \multicolumn{6}{|c|}{ White cells of blood. } & \multirow{3}{*}{$\stackrel{d}{a}$} \\
\hline & & & & & \multirow{2}{*}{ Total. } & \multicolumn{5}{|c|}{ Differential counts. } & \\
\hline & & & Prot. & Cells. & & P. & L. & H. & E. & O.c. & \\
\hline 1 & $\mathbf{M}$ & 58 & + & & $\begin{array}{r}7,400 \\
10,200\end{array}$ & $\begin{array}{l}52 \\
60\end{array}$ & 31 & $\begin{array}{l}7 \\
4\end{array}$ & $\overline{1}$ & $=$ & $100^{\circ}$ \\
\hline 2 & $\mathbf{M}$ & 50 & \pm & & $\begin{array}{l}6,400 \\
6,000\end{array}$ & $\begin{array}{l}74 \\
67\end{array}$ & 20 & $\begin{array}{l}3 \\
4\end{array}$ & $\begin{array}{l}2 \\
4\end{array}$ & $\begin{array}{l}1 \\
1\end{array}$ & $99^{\circ}$ \\
\hline 3 & $\mathbf{M}$ & 48 & \pm & SL \pm & 12,800 & $91 \cdot 5$ & 6 & 2 & - & .5 & 1040 \\
\hline 4 & $\mathbf{M}$ & 41 & + & SL+ & 9,200 & 69 & 25 & 5 & -1 & 1 & $104^{\circ}$ \\
\hline 5 & M & 40 & \pm & No $\mathbf{S L}$ & $\begin{array}{l}7,200 \\
5,800 \\
5,000\end{array}$ & $\begin{array}{l}57 \\
48 \\
54\end{array}$ & $\mid \begin{array}{l}37 \\
35 \\
39\end{array}$ & $\begin{array}{l}2 \\
4 \\
4\end{array}$ & \begin{tabular}{r|r}
4 & \\
12 & \\
2
\end{tabular} & $\begin{array}{l}\overline{1} \\
1\end{array}$ & $\frac{99^{\circ}}{-}$ \\
\hline 6 & $\mathbf{M}$ & 34 & \pm & SL nil & $\begin{array}{l}9,000 \\
6,400 \\
5.480 \\
8,600\end{array}$ & $\begin{array}{l}59 \\
73 \\
78 \\
65\end{array}$ & $\begin{array}{l}33 \\
23 \\
16 \\
30\end{array}$ & $\begin{array}{l}7 \\
3 \\
6 \\
5\end{array}$ & $\begin{array}{l}1 \\
\frac{1}{-}\end{array}$ & $=$ & $109^{\circ}$ \\
\hline 7 & M. & 33 & + & $\mathrm{SL}+$ & 7,000 & 52 & 41 & 6 & 1 & - & $103^{\circ}$ \\
\hline 8 & F & 23 & $\begin{array}{l} \pm \\
\pm\end{array}$ & $\begin{array}{l}\text { SI } \\
+\end{array}$ & $\begin{array}{l}9,000 \\
6,800\end{array}$ & $\begin{array}{l}86 \cdot 5 \\
72\end{array}$ & $\begin{array}{r}8 \cdot 5 \\
22\end{array}$ & 6 & 1 & $=$ & 100.5 \\
\hline 9 & $\mathbf{M}$ & 9 & * & $*$ & 4,000 & 35 & 58 & 6 & - & 1 & $101^{\circ}$ \\
\hline 10 & $\mathbf{M}$ & 7 & $? \pm$ & {$[ \pm$} & 21,200 & 88 & 10 & 2 & - & - & $104^{\circ}$ \\
\hline 11 & M & 4 & Nil & SL nil & $\begin{array}{r}14,000 \\
7,840\end{array}$ & $\begin{array}{l}75 \\
63\end{array}$ & $\begin{array}{l}19 \cdot 5 \\
32\end{array}$ & $\begin{array}{r}3 \cdot 5 \\
5\end{array}$ & 2 & $=$ & $101^{\circ}$ \\
\hline 12 & $\mathrm{~F}$ & 210 & 童 & $\begin{array}{c}\text { SL nil } \\
\pm\end{array}$ & 3,600 & $19 \cdot 5$ & $73 \cdot 5$ & 2 & 5 & $=$ & $102^{\circ}$ \\
\hline 13 & $\mathbf{F}$ & $1 \frac{1}{2}$ & +++ & $\begin{array}{l}+++ \text { T.B. } \\
\text { found. }\end{array}$ & 11,680 & 64 & 31 & 4 & 1 & - & $103^{\circ}$ \\
\hline 14 & M & 48 & & & 7,040 & 71 & 26 & 3 & - & - & $102^{\circ}$ \\
\hline 15 & $\mathbf{M}$ & $47^{\circ}$ & & & 8,800 & 63 & 32 & 7 & 2 & - & $99^{\circ}$ \\
\hline 16 & M & 6 & & & 7,400 & 72 & 21 & 5 & 1 & 1 & $103^{\circ}$ \\
\hline 17 & $F$ & 6 & & & 11,600 & 85 & 13 & 2 & - & - & $105^{\circ}$ \\
\hline 18 & $\mathbf{M}$ & 5 & & & 10,000 & 55 & 42 & 1 & 2 & - & $104^{\circ}$ \\
\hline 19 & M & 5,12 & & & 10,000 & 18 & 75 & 4 & 2 & 1 & $101^{\circ}$ \\
\hline 20 & $M$ & 4 & & & 12,400 & 38 & 57 & 2 & 3 & - & -1 \\
\hline
\end{tabular}

Prot., protein. P., polynuclears. L., lymphocytes, large and small. H., hyalines. E., eosinophils. O.C., other cells. SL., small lymphcytes. Max. temp., Maximum temperature recorded during attack.

* $\frac{1}{2}$ e.cm. only, not sufficient to examine. † Cerebro-spinal filuid, rot. +++ tine cobweb; Cells-SL, 60 per cent.; $\mathbf{P}, 40$ per cent $\pm=$ Very slight excess of protein or of cells up to 10 per c.mm. $+=$ Slight excess of protein or of cells up to 20 per c.mm. $+++=$ Marked excess of protein or of cells up to 100 and over per $\mathrm{c} . \mathrm{mm}$. Remarks.-Case 1. Drowsy; ptosis; delirious. Case 2. Drowsy; ptosis. Case 3. Died. Anaerobic blood culture negative. Ptosis; rash; drowsy. Case 4. Died. Landry's type. Case 5. Ptosis ; later facial paralysis. Case 6 . Drowsy; ptosis. Unfortunately spinal fluid was not examined a second time. Anaerobic blood culture negative. drowsy; chorea: ? T.B. Case 10. Drowsy lobar pneumonia. Case 11. Delirious ; irritable. Case $1^{3}$. This blood count pneumonia. Case 11. admission; ? ptosis. Case 13. Died. Drowsy ; proved on P.M. T.B. Case 14. Died; delirious; drowsy. Case 15. Ptosis ; mental and speech slurring. Case 16. Drowsy. Case 17 . Vomiting and abdominal pain. Case 18. Irritability. Case 19. Drowsy. Case æ0. Ptosis; convalescent.
Twenty cases were examined, all of which were considered to be examples of epidemic encephalitis. In all cases the blood was examined and in 12 cases the spinal fluid also. (See Table.)

In 2 cases the diagnosis was proved to be erroneous. Case 10, with a high leucocyte count and a practically normal spinal fluid, developed a typical attack of pneumonia. Case 13 had tubercle bacilli in spinal fluid and this result was confirmed post mortem. In the remaining 18 cases, with the possible exception of one or two doubtful ones, there was every reason to suppose that the diagnosis was correct.

Leucocyte counts. - With the exception of Case 10, which turned out to be pneumonia, in no case has the leucocyte count been as high as even 15,000 per c.mm

In 18 counts done on 10 adults the average number of leucocytes was roughly 7600 per c.mm., while the average of 13 counts on 5 typical cases (Nos. 1, 2, 5, 6, and 8) was 7000 per c.mm. The average of 9 counts in children was about 9000 cells per c.mm. The normal number of white cells was found to be between 5000 and 6000 per c.mm. in gdults and about 8000 per c.mm. in children. Thus it will appear that there is a small leucocytosis in cases of epidemic encephalitis both in adults and children.

Of the 4 fatal cases (Nos $3,4,13,14$ ) No. 13, with a count of 11,680 , turned out to be tuberculous, while No. 3, with a count of 12,800 , had a generalised hæmorrhagic rash and also a bedsore, which account for the inflammatory condition of his blood. The remaining two had counts of 9200 and 7040 .

The counts in children in general were found to be higher. In view of the high count of one fatal case with tuberculons meningitis (No. 13) it is a pity that the spinal fluid was not available for examination in these cases.

As regards the question of leucopenia, it can be stated that no leucopenia was found in these cases. Cases 9 and 12, with counts of 4000 and 3600 , were both doubtful cases.

The average number of polymorphonuclear leucocytes was found to be 66 per cent. in adults and 45 per cent. in children. As the average number of these white cells in normal counts is about 60 per cent. in adults and 40 per cent. in children, it would appear from the averages that there was only a slight tendency to polymorphonuclear increase. However, there were a few counts in which the relative proportion of polymorphonuclear leacocytes had decidedly increased.

Cerebro-spinal fluid.-The spinal fluids examined either showed nothing abnormal or only a small excess of protein and a small excess of cells which were found to be small lymphocytes. The fluids were in all cases practically clear and in no case was opalescence noticed. Case 13, which had a cobweb and a very large excess of protein and cells was proved to be tuberculous.

\section{Conolusions.}

1. The very small amount of leucocytosis-viz., 8000 to 9000 per c.mm. - in cases of epidemic encephalitis falls far short of the pronounced leucocytosis-viz., 15,000 to 30,000recorded at the Rockefeller Institute in cases of poliomyelitis.

2. The cerebro-spinal fluid is not as grossly affected as in poliomyelitis in which often cell counts running into several hundreds and sometimes exceeding 1000 per c.mm. have been recorded. As a matter of fact, the deviation from the normal is very small.

3 . In view of the very small deviation from the normal both of the blood and the spinal fluid in cases of epidemic encephalitis, and especially in the absence of successful experimental communication of the disease to monkeys with the production of paralysis, in my opinion we are not justified in asserting that the virus of epidemic encephalitis is the same as in poliomyelitis.

4. Although the results of the examinations of the blood and the spinal fluid afford no positive proof in support of a diagnosis of epidemic encephalitis, such negative results will materially help in ruling out a number of other obscure cerebral conditions, as was found to be the case in those due to pneumunia and tuberculous meningitis recorded above. It is therefore considered advisable to have recourse to such examinations in all cases likely to be classed as those of epidemic encephalitis on clinical grounds.

I am very much indebted to my chief, Dr. P. N. Panton, for his very valuable advice and guidance. I am also much obliged to my colleague, Dr. Harold E. Bates, for his helpful criticisms and suggestions. 